\title{
Subclinical myasthenia gravis in thymomas
}

Citation for published version (APA):

Marcuse, F., Hochstenbag, M., Hoeijmakers, J. G. J., Hamid, M. A., Damoiseaux, J., Maessen, J., \& De Baets, M. (2021). Subclinical myasthenia gravis in thymomas. Lung Cancer, 152, 143-148.

https://doi.org/10.1016/j.lungcan.2020.12.010

Document status and date:

Published: 01/02/2021

DOI:

10.1016/j.lungcan.2020.12.010

Document Version:

Publisher's PDF, also known as Version of record

Document license:

Taverne

Please check the document version of this publication:

- A submitted manuscript is the version of the article upon submission and before peer-review. There can be important differences between the submitted version and the official published version of record.

People interested in the research are advised to contact the author for the final version of the publication, or visit the DOI to the publisher's website.

- The final author version and the galley proof are versions of the publication after peer review.

- The final published version features the final layout of the paper including the volume, issue and page numbers.

Link to publication

\footnotetext{
General rights rights.

- You may freely distribute the URL identifying the publication in the public portal. please follow below link for the End User Agreement:

www.umlib.nl/taverne-license

Take down policy

If you believe that this document breaches copyright please contact us at:

repository@maastrichtuniversity.nl

providing details and we will investigate your claim.
}

Copyright and moral rights for the publications made accessible in the public portal are retained by the authors and/or other copyright owners and it is a condition of accessing publications that users recognise and abide by the legal requirements associated with these

- Users may download and print one copy of any publication from the public portal for the purpose of private study or research.

- You may not further distribute the material or use it for any profit-making activity or commercial gain

If the publication is distributed under the terms of Article $25 \mathrm{fa}$ of the Dutch Copyright Act, indicated by the "Taverne" license above, 


\title{
Subclinical myasthenia gravis in thymomas
}

\author{
Florit Marcuse ${ }^{\mathrm{a}, \mathrm{b}, *}$, Monique Hochstenbag ${ }^{\mathrm{a}}$, Janneke G.J. Hoeijmakers ${ }^{\mathrm{b}, \mathrm{c}}$, \\ Myrurgia Abdul Hamid ${ }^{\mathrm{d}}$, Jan Damoiseaux ${ }^{\mathrm{e}}$, Jos Maessen ${ }^{\mathrm{f}}$, Marc De Baets ${ }^{\mathrm{b}}$ \\ ${ }^{a}$ Department of Pulmonology, Maastricht University Medical Center+, Maastricht, the Netherlands \\ ${ }^{\mathrm{b}}$ School for Mental Health and Neuroscience, Maastricht University, Maastricht, the Netherlands \\ ${ }^{\mathrm{c}}$ Department of Neurology, Maastricht University Medical Center+, Maastricht, the Netherlands \\ ${ }^{\mathrm{d}}$ Department of Pathology, Maastricht University Medical Center+, Maastricht, the Netherlands \\ e Central Diagnostic Laboratory, Maastricht University Medical Center+, Maastricht, the Netherlands \\ ${ }^{\mathrm{f}}$ Department of Cardiothoracic Surgery, Maastricht University Medical Center+, Maastricht, the Netherlands
}

\section{A R T I C L E I N F O}

\section{Keywords:}

Thymomas

Thymectomy

Myasthenia gravis

Anti-acetylcholinereceptor-antibodies

\begin{abstract}
A B S T R A C T
Background: A proportion of thymoma-patients without a history of myasthenia gravis (MG) before thymectomy, appears to have positive anti-AChR-antibodies in the serum. These subclinical MG-patients could be underdiagnosed because analyzation of anti-AChR-antibodies in thymomas is not always performed in patients who did not experience neurological symptoms. The prevalence and long-term outcomes of subclinical MG are never described in literature yet.

Methods: We retrospectively analyzed 398 consecutive patients who underwent a robotic-assisted thoracoscopic surgery at the Maastricht University Medical Center+ (MUMC+) between April 2004 and December 2018. In the MUMC+, a robotic approach is the standard surgical approach in patients with thymic diseases. Inclusion criteria were thymomas, thymectomy performed in the MUMC + with a follow-up of at least one year and age above 18 years old. Exclusion criteria were patients with thymic carcinomas, refused participation, or those who were lost to follow-up.

Results: Of the 102 included thymoma-patients, 87 patients (85\%) were tested for anti-AChR-antibodies before thymectomy, of which 57 patients were diagnosed with clinical MG and seven subclinical MG-patients were found. Of the 15 patients who were not tested for anti-AChR-antibodies, four more subclinical MG-patients were discovered in the years after thymectomy. The median follow-up time was 62 months. In total, 11 subclinical MG-patients were found, with a mean age of 54 years and predominantly females (64 \%). Ten subclinical MGpatients $(91 \%)$ developed clinical-MG, within six years after thymectomy. Immunosuppressive drugs were prescribed in five patients. Four patients were diagnosed with a recurrence of the thymoma. No surgical mortality was reported. Two patients died due to a myasthenic crisis.

Conclusions: The prevalence of subclinical MG in thymomas was found to be $10.8 \%$. One in four patients who experienced no neurological symptoms before thymectomy, appeared to have anti-AChR-antibodies and $91 \%$ of these patients developed clinical MG within six years after the thymectomy. Analyzing anti-AChR-antibodies in the serum is recommended in all suspected thymomas before a thymectomy is performed.
\end{abstract}

\section{Introduction}

Myasthenia gravis (MG), a rare auto-immune disorder featured by muscle weakness, is found in $20-25 \%$ of the patients with a thymoma. Almost all thymoma-patients with MG have anti-AChR-antibodies [1]. In our center, we have discovered a proportion of thymoma-patients that appears to have positive anti-AChR-antibodies in the serum without neurological symptoms before the thymectomy. We have defined this population as seropositive patients without clinical symptoms in the medical history, thus a subclinical variant of the more commonly described clinical MG. The existence, the prevalence and long-term outcomes of subclinical MG are not described in previous literature yet. Testing anti-AChR-antibodies in patients, when a diagnosis of a thymic epithelial tumor is suspected, is mentioned sporadically in evidence-based guidelines [2,3]. However, some thymoma-patients without neurological symptoms are not analyzed for

\footnotetext{
* Corresponding author at: Maastricht University Medical Center, Department of Pulmonology, Postbox 5800, 6202 AZ, Maastricht, the Netherlands.

E-mail address: florit.marcuse@mumc.nl (F. Marcuse).
} 
anti-AChR-antibodies in the serum, nor seen by a neurologist if there are no clear symptoms of muscle weakness. When the antibody status is unknown before surgery, optimal precautions are not considered adequately. An optimal pre-evaluation of MG-patients is necessary for adequate drug treatment, anesthetics and ventilation during the thymectomy and for minimizing the risk for a postoperative myasthenic crisis [4].

Myasthenia gravis has a potentially deadly outcome due to a myasthenic crisis with respiratory failure [5]. MG is characterized by fluctuating muscle weakness, fatigability and exhaustion of skeletal muscles, especially worsening upon exertion. Autoantibodies in MG are acting against the acetylcholine receptor (anti-AChR), muscle-specific tyrosine kinase (anti-MuSK), or lipoprotein receptor-related protein four (anti-LRP4) [6,7]. MG is diagnosed by medical history and physical examination and can be confirmed by electromyography and autoantibodies in the serum $[8,9]$. The prevalence of clinical MG and MG-associated-thymomas in the Netherlands was found to be 167 and 13 per million inhabitants respectively $[10,11]$. The negative predictive value of analyzing anti-AChR-antibodies is $100 \%$ in thymoma-patients with late-onset myasthenia gravis (LOMG) and $99.5 \%$ in thymoma-patients with early-onset myasthenia gravis (EOMG) [12]. There are several pathogenic mechanisms found in patients with a thymoma. One of the triggers, in thymoma-patients, irrespective of MG-status, is a defective expression of the autoimmune regulator (AIRE). This protein is a transcription factor in the medulla of the thymus that drives ectopic expression of peripheral tissue-specific autoantigens, including the AChR- $\alpha$-subunit. In $95 \%$ of all patients with a thymoma, the failure to express AIRE is a possible contribution in disturbed pathways involved in autoimmunity [13,14]. Most thymomas have a slow grow pattern with overall benign features. However, in all patients with a thymoma, a thymectomy should be performed because a thymoma could have a potential malignant behavior with a risk for invasiveness and metastatic disease. A robotic thymectomy is safe and feasible in early-stage thymomas and some selected advanced thymomas [15-18]. Furthermore, a thymectomy improves clinical outcomes over a 5-year period in patients with nonthymomatous MG who have anti-AChR-antibodies [19,20]. Therefore, a thymectomy is recommended in all patients with positive anti-AChR-antibodies, even in the case that the presence of a thymoma is less likely. Because pulmonary oncologists are the center point in the treatment of patients with a thymoma, it is essential to have a clear overview of the potential risks of paraneoplastic syndromes, like (subclinical) myasthenia gravis.

This retrospective study aims to investigate the prevalence of subclinical MG in patients with a thymoma and to analyze the long-term outcomes of these patients after thymectomy.

\section{Patients and methods}

We retrospectively analyzed all consecutive 398 patients who underwent a robotic-assisted thoracoscopic surgery (RATS), using the DaVinci Robotic System at the Maastricht University Medical Center+ (MUMC+) between April 2004 and December 2018. This study was approved by the medical ethical commission of the MUMC + in 2019. In the MUMC+, a robotic approach is the standard surgical approach in patients with thymic diseases. The MUMC + is the principal referral center in the Netherlands for robotic thymectomy in patients with thymomas and myasthenia gravis. Because most of the patients were referred to the MUMC + only for the thymectomy, the follow-up data for the neurological and oncological status after thymectomy was requested in the referring hospitals with consent of the patients (written permission). Inclusion criteria were: pathologically proved thymomas, a thymectomy performed in the MUMC + with a follow-up of at least one year and age above 18 years old. Exclusion criteria were: thymic carcinomas, refused permission by the patient for requesting data in the referring hospital and patients who were lost to follow-up. Anti-AChR-antibodies were measured by radio immune assay (RIA) or enzyme-linked immunosorbent assay (ELISA) in the referring hospital. In RIA, the antibodies were found positive in case of $>0.25 \mathrm{nmol} / \mathrm{L}$ and in ELISA, cutoff values provided by the manufacturers were applied. The clinical severity of MG was classified by the criteria of the Myasthenia Gravis Foundation of America (MGFA). Subclinical MG was defined as positive anti-AChR-antibodies in the serum, without previous clinical MGsymptoms. All the MGFA scores were retrospectively examined by the same blinded physician. Thymomas were histologically classified by the WHO Histological Classification of Thymomas. The tumor invasion was classified by the Masaoka-Koga Staging System and TNM Classification of Malignant Tumors.

\section{Results}

From April 2004 until December 2018, a total of 398 patients underwent a robotic thymectomy in the MUMC + . A robotic thymectomy was performed in 130 patients for a thymoma, of which 102 patients (78.5 \%) were included and 28 patients $(21.5 \%)$ were excluded based on the study criteria. A flow chart of this study is shown in Fig. A1 in Appendix A. Of the 28 excluded patients with a thymoma, seven patients had an objection against participating in this follow-up study and did not give permission for requesting their data at the hospitals where they were treated. Six patients died in the years before the start of this study. Of the remaining 15 patients, some patients migrated outside the country or were not answering the request for permission. Patients were excluded from this study if they still not answered the request after four attempts.

The pre-surgical MGFA was based on the clinical status at the last outpatient clinic before the thymectomy, at the latest three months before surgery. The median follow-up time was 62 months (range: 13-153 months). Of the 102 included patients with a suspected thymoma, 87 patients $(85.3 \%)$ were analyzed for anti-AChR-antibodies prior to the thymectomy. Of the 58 patients who were diagnosed with clinical MG in the months before the thymectomy (range: 2-120 months), 57 patients had positive anti-AChR-antibodies. The patient characteristics of all included patients are shown in Table B1 in Appendix B. One patient had a negative AChR-test, despite the presence of clinical MG-symptoms. Anti-MuSK-antibodies or anti-LRP4antibodies were not analyzed in the referring hospital. Thymomas in anti-MuSK-antibody positive patients are seldom described, but very rare. Seven subclinical MG-patients were discovered prior to the thymectomy, and medical precautions (e.g. fewer muscle relaxants in anesthesia, extra monitoring of neuromuscular- and respiratory status, etc.) were made during the thymectomy and hospital stay. Of the 15 patients $(14.7 \%)$ who were not analyzed for anti-AChR-antibodies prior to the thymectomy, four patients were discovered with positive antiAChR-antibodies in the years after the thymectomy. These four patients developed newly diagnosed muscle weakness and consulted a neurologist. The remaining 10 thymomas who were never analyzed for anti-AChR-antibodies, did not consult a neurologist and did not develop neurological symptoms as far as the follow-up has shown.

In a total of 102 thymomas, 44 patients did not experience MGsymptoms before the thymectomy. Follow-up showed that of this group of 44 patients, a total of 11 patients were eventually found with positive anti-AChR-antibodies. Thus, of the patients without MGsymptoms before the thymectomy, $25 \%$ of these patients appeared to have anti-AChR-antibodies in the serum. Seven out of 11 patients were diagnosed before thymectomy and four out of 11 patients were diagnosed after thymectomy. In all 102 included thymomas, the presence of 11 patients with subclinical MG leads to a prevalence of subclinical MG of $10.8 \%$. A specific overview of the patients with subclinical MG is shown in Table C1 in Appendix C. Of the 11 subclinical MG-patients, 10 patients (91\%) developed clinical MG (range MGFA 1-4B). Symptoms of MG started from one day till 74 months after the thymectomy (median time: 28 months). Immunosuppressive drugs were prescribed in five patients (45\%). Advanced stage thymomas (Masaoka-Koga stage $\geq$ III) 
were found in four subclinical MG-patients (36 \%). In one patient, no tumor size was reported in the pathological report. In de rest of the group, tumor sizes were found between $25-105 \mathrm{~mm}$ (median size: $62 \mathrm{~mm}$ ). One patient underwent an extended robotic thymectomy with access ports on both sides of the thorax. No conversions to thoracotomy or sternotomy were reported in subclinical MG-patients.

Five patients with subclinical MG (45\%), of whom two patients underwent debulking surgery, were diagnosed with a recurrence of the thymoma after the thymectomy (median time, 47 months; range 7-85 months). Four out of five patients who were diagnosed with a recurrence, have received adjuvant radiotherapy after thymectomy $(50-60 \mathrm{~Gy}$ in 25-30 fractions). All subclinical MG-patients with a recurrence were diagnosed with a B2-thymoma. Two patients with subclinical MG were treated with chemotherapy after the thymectomy. One of these patients received adjuvant cisplatin-etoposide and the other patient, who also underwent neoadjuvant chemotherapy (cisplatin-etoposide), received second-line paclitaxel-carboplatin.

No surgical mortality was reported. Three out of 11 subclinical MGpatients died during follow-up.

The first patient (patient I) developed MG-symptoms 72 months after surgical resection. He initially started with Pyridostigmine, but he started with Prednisone as well after the MG-symptoms worsened. In the meantime, he developed a recurrence of the B2-thymoma with pleural metastasis, 85 months after the thymectomy. Due to the extensiveness of the metastasis, surgical treatment was not an option. The patient preferred to wait with chemotherapy and best support of care was provided. He died 99 months after the thymectomy in the hospital, where he was treated with Prednisone and IVIG for a myasthenic crisis, that was probably triggered after Prednisone was tapered at home. The most likely cause of death was reported as an asystolic cardiac arrest after he was collapsed in the hospital bed and did not respond to cardiopulmonary resuscitation. At the request of the family, no obduction was performed.

The second patient (patient $\mathrm{J}$ ), with a mass in the anterior mediastinum and suspected pleural metastasis on PET-CT, first underwent mediastinoscopy and bronchoscopy. Because both results were negative, the multidisciplinary medical team decided to perform a wedge resection and a pleural biopsy. The biopsy showed a B2-thymoma. A complete resection was initially purposed but converted to debulking surgery. Multiple pleural metastases were found and the brachiocephalic vein was totally encapsulated and invaded by tumor tissue. Clips on the borders of the surgical resection were left. Adjuvant radiotherapy was suggested but due to the progression of multiple metastases and a newly suspected supraclavicular metastasis, local therapy was not an option. The patient started with cisplatin-etoposide and after a short period of tumor regression, he showed progression after three months of chemotherapy. Molecular analysis of the previous resected tissue showed no mutations, and 68Ga-DOTATOC PET/CT imaging was found negative. Second-line chemotherapy (cisplatin- doxorubicin- cyclophosphamide) was suggested, but the patient preferred to wait. He developed a superior vena cava syndrome and a superior vena cava stent was placed, followed by palliative radiotherapy. In the meantime, the patient developed MG-symptoms, 24 months after the thymectomy, and was treated with Pyridostigmine and Prednisone. More than a year later, the patient experienced dyspnea with progressive weakness of ocular and bulbar muscles after Prednisone was tapered. The cardiac evaluation showed no pathological abnormalities and a pulmonary embolism was excluded by CT-imaging. IVIG was suggested, but the patient preferred to die at home instead of hospitalization. He died 39 months after the thymectomy.

The third patient (patient $\mathrm{K}$ ) had an advanced stage IVa thymoma with implants in the pleura, lung, pericardium, and both phrenic nerves. Therefore, a complete resection (R0) was not feasible. He first received neoadjuvant chemotherapy and after surgical resection, he received local adjuvant radiotherapy. Seven months after the thymectomy, he developed a recurrence of the thymoma with pleural implants.
Molecular analysis showed no mutations. A surgical or radiological treatment was not an option due to the extensiveness of the disease. After two cycles of second-line chemotherapy (paclitaxel-carboplatin), the patient developed pneumonia and died after antibiotic treatment, 16 months after the thymectomy. He developed no myasthenic symptoms during his follow-up of 16 months.

\section{Discussion}

In this retrospective study, we found a prevalence of $10.8 \%$ of subclinical myasthenia gravis in patients with a thymoma who underwent a thymectomy. Of the patients without neurological symptoms before the thymectomy, $25 \%$ of these patients appear to have positive anti-AChR-antibodies. Of the subclinical MG-patients, $91 \%$ of these patients developed clinical symptoms within six years after the thymectomy.

If subclinical patients developed MG-symptoms, it was on average at 28 months after the thymectomy. Therefore, we think that the one and only patient who did not develop MG-symptoms and died at 16 months after the thymectomy, had a follow-up period that was possibly too short for the development of clinical significant MG-symptoms. Since nearly all subclinical MG-patients in our series developed MG-symptoms and some patients need to be treated with immunosuppressive drugs, it is now clear that mild to severe MG can develop for many years after the thymectomy in patients with a thymoma who never experienced MGsymptoms before thymectomy. Because there is no previous literature on this topic, it is hard to compare our results with other centers. However, the results in this study should be an eye-opener and emphasize the importance of analyzing anti-AChR-antibodies in all suspected thymomas before a thymectomy is performed.

In the last two decades, more guidelines for the treatment of thymic tumors were developed. Patients with a suspected thymoma and positive anti-AChR-antibodies without MG-symptoms have never been described as a group that needs extra attention during preoperative evaluation and postoperative follow-up. Because pre-surgical blood-analysis is a standard in all patients, ordering a test for anti-AChR-antibodies is a minor addition for the physician. Patients with positive anti-AChR-antibodies are at risk for the development of myasthenic symptoms during hospitalization and after discharge from the hospital. Medical precautions are performed in all patients with positive anti-AChR-antibodies, for example adequate drug treatment, fewer muscle relaxants in anesthetics, more adjusted ventilation during the thymectomy, and minimizing the risk for a postoperative myasthenic crisis [3]. If the antibody status is unknown before the thymectomy, patients with undiagnosed subclinical MG will receive an incomplete presurgical evaluation. The presence of anti-AChR-antibodies is also a warning for the future because it is now clear that most subclinical MG-patients will develop clinical MG. It is important to inform the patients with subclinical MG about what the future can reveal, by creating attention and awareness of MG during a neurological consultation before the thymectomy.

Furthermore, our series showed two patients with subclinical MG who were treated with adjuvant and second-line chemotherapy and one of them received neoadjuvant chemotherapy as well. Both chemotherapy and checkpoint-inhibitors, could increase MG-symptoms and may have to be reconsidered for all patients with a thymoma and positive anti-AChR-antibodies [21-23]. For example, the presence of anti-AChR-antibodies put patients with a thymoma at risk for developing myositis after treatment with avelumab, an immune checkpoint inhibitor targeting programmed death-ligand 1 (PDL-1) [24].

Previous research proved the safety and feasibility of minimally invasive techniques for patients with early-stage thymomas and selected advanced stage thymomas [15-18]. For this reason, all the suspected thymomas in our center were initially operated by robotic-assisted thoracoscopic surgery if computer tomography precluded no invasion of tumor in greater thoracic vessels [25]. In this study, no conversions to thoracoscopy or sternotomy were reported in patients with subclinical 
MG. In our total group of patients with a thymoma, seven recurrences occurred of which five patients were diagnosed with subclinical MG. Although a low recurrence rate was found in the groups with clinical MG (3\%) and without MG (3\%), the recurrence rate in the group with subclinical MG is higher (45\%), despite adjuvant radiotherapy was performed in $80 \%$ of these patients. Of the five patients with a recurrence, two recurrences were pre-surgically expected due to invasive stage IV disease. Possibly, there is an association between the recurrence rate and the higher amount of advanced staged thymomas in the group with subclinical MG. To analyze the clinical significance of this possible association, a larger amount of patients is required for further research.

The present study has several limitations. First, MG is frequently described as a paraneoplastic syndrome in patients with thymomas but the prevalence in our series was found higher compared with previous literature, as a result of a referral bias [12,26,27]. In the Netherlands, the MUMC + is the principal tertiary hospital for performing robotic thymectomies in thymomas and MG. Last years, more thymectomies are performed in patients with MG after the randomized MGTX-trial of Wolfe et al. $[19,20]$. Secondly, a possible selection bias is caused by the necessary permission of the patient for requesting their follow-up data in the referring hospitals. Furthermore, the follow-up was performed at the referring hospitals which may have resulted in different decisions regarding the drug treatment and oncological follow-up after the thymectomy. Finally, subgroup analyses and comparative statistical analyses were not feasible in this study due to a relatively small group of patients with subclinical MG.

A study with a larger group of patients may lead to more specific predictors of disease in patients with subclinical MG. Furthermore, it could be interesting to analyze the serum levels of anti-AChR-antibodies in patients with subclinical MG with respect to possible predictive value.

\section{Conclusions}

In this study, the prevalence of subclinical MG in thymomas was found to be $10.8 \%$. And one in four patients who experienced no neurological symptoms before the thymectomy, appeared to have antiAChR-antibodies. At least $91 \%$ of the patients with subclinical MG developed clinical MG within six years after the thymectomy. Analyzing anti-AChR-antibodies is recommended in all suspected thymomas and should be part of the pre-surgical screening by the pulmonary oncologist. It is malpractice if the antibody status is unknown at the time of a thymectomy. Diagnosing positive anti-AChR-antibodies will lead to a complete presurgical evaluation, specific medical precautions during the hospital stay and personalized treatment after the thymectomy, including oncological- and neurological therapy. Further research is required for performing comparative statistical analyses and specific predictors of disease.

\section{Informed consent}

Approval of ethics committee (non-WMO research).

\section{CRediT authorship contribution statement}

Florit Marcuse: Methodology, Formal analysis, Investigation, Data curation, Writing - original draft, Visualization. Monique Hochstenbag: Conceptualization, Resources, Writing - review \& editing, Supervision. Janneke G.J. Hoeijmakers: Resources, Writing - review \& editing. Myrurgia Abdul Hamid: Resources, Validation, Writing - review \& editing. Jan Damoiseaux: Resources, Validation, Writing - review \& editing. Jos Maessen: Methodology, Resources, Writing - review \& editing. Marc De Baets: Resources, Validation, Writing - review \& editing, Supervision, Project administration.

\section{Declaration of Competing Interest}

No conflicts of interest were reported by the authors.

\section{Acknowledgments}

We are grateful to all participating departments in the 60 hospitals in the Netherlands who contributed to this study. We also like to thank all MG and thymoma patients for their participation.

\section{Appendix A}

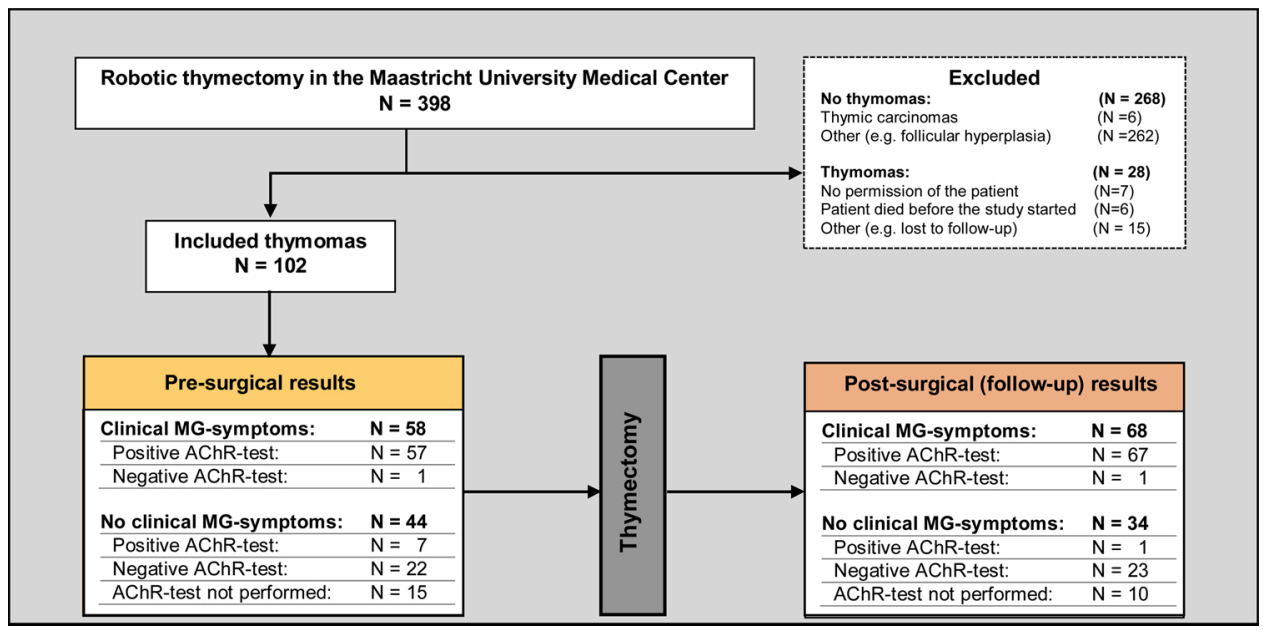

Fig. A1. Flowchart.

Legend: Before thymectomy, seven patients without clinical MG-symptoms and positive antiAChR-antibodies were found. In the group of patients who were initially not analyzed before thymectomy, four more patients with positive antiAChR-antibodies were found in the years after thymectomy. The prevalence of subclinical MG in all included thymomas was found $10.8 \%$. One in four patients (25 \%) without clinical MGsymptoms before thymectomy, appeared to have positive anti-AChR-antibodies. Of this group, 10 out of 11 patients (91\%) developed clinical MG after thymectomy. 
Appendix B

Table B1

Patient characteristics of all included thymomas.

\begin{tabular}{|c|c|c|c|}
\hline & \multicolumn{3}{|l|}{ Thymomas } \\
\hline & $\begin{array}{l}\text { Clinical } \\
\text { myasthenia } \\
\text { gravis }\end{array}$ & $\begin{array}{l}\text { Subclinical } \\
\text { myasthenia } \\
\text { gravis }\end{array}$ & $\begin{array}{l}\text { No myasthenia } \\
\text { gravis }\end{array}$ \\
\hline Patients, $\mathrm{n}$ & 58 & 11 & 33 \\
\hline Female, n (\%) & $30(52 \%)$ & $7(64 \%)$ & $17(52 \%)$ \\
\hline Mean age at surgery, years & 55.04 & 54.36 & 65.05 \\
\hline $\begin{array}{l}\text { Median length of follow- } \\
\text { up, months }\end{array}$ & 61 & 65 & 57 \\
\hline $\begin{array}{l}\text { Median duration of MG } \\
\text { before thymectomy, } \\
\text { months (range) }\end{array}$ & $16(2-120)$ & - & - \\
\hline $\begin{array}{l}\text { Anti-AChR-antibodies, } \mathrm{n} \\
\quad(\%)\end{array}$ & $57(98 \%)$ & $11(100 \%)$ & $\begin{array}{l}\text { In } 23 \text { patients: } 0 \% \\
\text { In } 10 \text { patients: not } \\
\text { measured }\end{array}$ \\
\hline \multicolumn{4}{|l|}{$\begin{array}{c}\text { Therapy for MG at } \\
\text { surgery, } \mathrm{n}(\%)\end{array}$} \\
\hline No therapy & $2(3 \%)$ & $11(100 \%)$ & - \\
\hline $\begin{array}{l}\text { Anticholinesterase } \\
\text { monotherapy }\end{array}$ & $24(42 \%)$ & - & - \\
\hline Immunosuppressive drugs & $32(55 \%)$ & - & - \\
\hline \multicolumn{4}{|l|}{$\begin{array}{l}\text { Pre-surgical MGFA } \\
\text { classification (at the } \\
\text { latest } 3 \text { months before } \\
\text { thymectomy), n (\%) }\end{array}$} \\
\hline 0 & $2(3 \%)$ & $11(100 \%)$ & - \\
\hline I & $13(22 \%)$ & - & - \\
\hline $\mathrm{IIA}+\mathrm{IIB}$ & $31(54 \%)$ & - & - \\
\hline IIIA + IIIB & $10(17 \%)$ & - & - \\
\hline IVA + IVB & $1(2 \%)$ & - & - \\
\hline $\mathrm{V}$ & $1(2 \%)$ & - & - \\
\hline $\begin{array}{l}\text { Neoadjuvant } \\
\text { chemotherapy, n (\%) }\end{array}$ & $1(2 \%)$ & $1(9 \%)$ & $2(6 \%)$ \\
\hline $\begin{array}{l}\text { Thymoma diameter } \\
>50 \mathrm{~mm}, \mathrm{n}(\%)\end{array}$ & $19(33 \%)$ & $5(45 \%)$ & $17(52 \%)$ \\
\hline \multicolumn{4}{|l|}{$\begin{array}{l}\text { WHO histological type, } \mathrm{n} \\
\text { (\%) }\end{array}$} \\
\hline A & $6(10 \%)$ & $2(18 \%)$ & $4(12 \%)$ \\
\hline $\mathrm{AB}$ & $10(17 \%)$ & $1(9 \%)$ & $14(42 \%)$ \\
\hline B1 & $1(2 \%)$ & $0(0 \%)$ & $5(15 \%)$ \\
\hline B2 & $26(45 \%)$ & $7(64 \%)$ & $6(18 \%)$ \\
\hline B3 & $15(26 \%)$ & $1(9 \%)$ & $2(6 \%)$ \\
\hline Micronodular & $0(0 \%)$ & $0(0 \%)$ & $1(3 \%)$ \\
\hline \multicolumn{4}{|l|}{ Staging, n (\%) } \\
\hline Early stage thymomas* & $51(88 \%)$ & $7(64 \%)$ & $28(85 \%)$ \\
\hline $\begin{array}{l}\text { Advanced stage } \\
\text { thymomas }\end{array}$ & $7(12 \%)$ & $4(36 \%)$ & $5(15 \%)$ \\
\hline $\begin{array}{l}\text { Adjuvant radiotherapy, } \mathrm{n} \\
\text { (\%) }\end{array}$ & $21(36 \%)$ & $5(45 \%)$ & $\begin{array}{l}2 \text { performed ( } 6 \% \text { ) } \\
\text { and } 2 \\
\text { recommended but } \\
\text { refused by patient }\end{array}$ \\
\hline $\begin{array}{l}\text { Adjuvant/second-line } \\
\text { chemotherapy, n (\%) }\end{array}$ & $0(0 \%)$ & $2(18 \%)$ & $0(0 \%)$ \\
\hline Recurrence, n (\%) & $2(3 \%)$ & $5(45 \%)$ & $1(3 \%)$ \\
\hline $\begin{array}{l}\text { Mortality after } \\
\text { thymectomy, n (\%) }\end{array}$ & $5(9 \%)$ & $3(27 \%)$ & $5(15 \%)$ \\
\hline
\end{tabular}

WHO: World Health Organization; MGFA: Myasthenia Gravis Foundation of America.

* Early stage thymomas: Masaoka-Koga stages I and II / TNM < T3NOMO.

** Advanced stage thymomas: Masaoka-Koga stages III and IV / TNM $\geq$ T3NOMO.

\section{Appendix C}

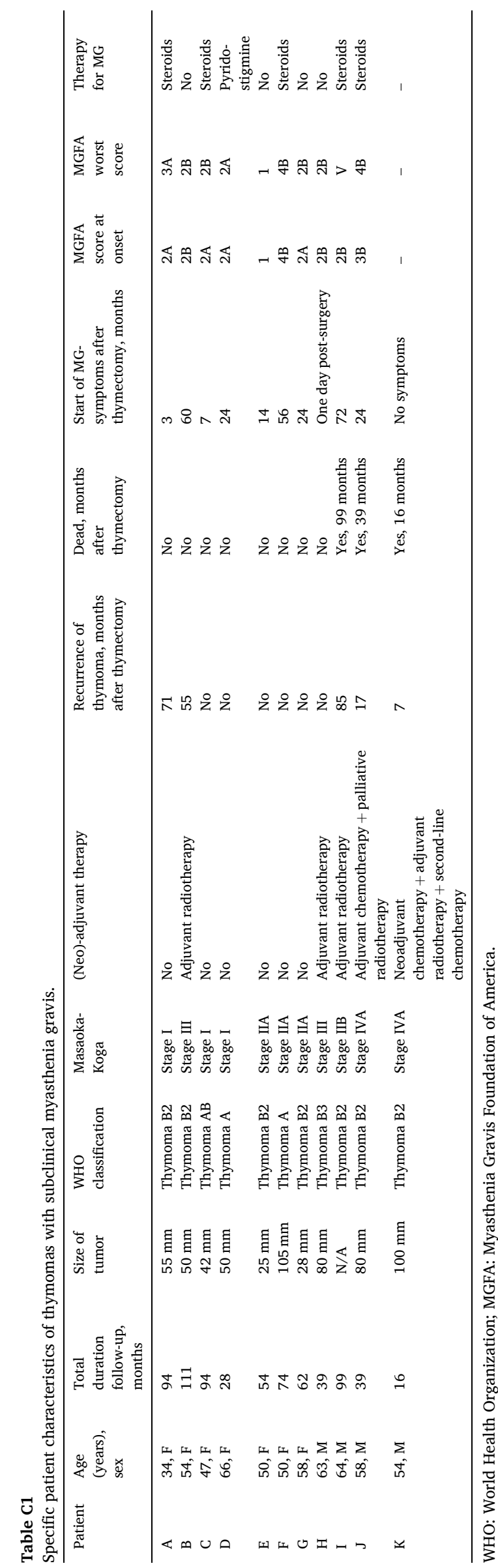




\section{References}

[1] M. Lucchi, R. Ricciardi, F. Melfi, et al., Association of thymoma and myasthenia gravis: oncological and neurological results of the surgical treatment, Eur. J. Cardio-Thoracic Surg. 35 (May (5)) (2009) 812-816.

[2] N. Girard, E. Ruffini, A. Marx, et al., Thymic epithelial tumours: ESMO clinical practice guidelines, Ann. Oncol. 26 (suppl 5) (2015) v40-v55.

[3] C. Falkson, A. Bezjak, G. Daling, et al., The management of thymoma: a systematic review and practice guideline, J. Thorac. Oncol. 4 (2009) 911-919.

[4] L. Blichfeldt-Lauridsen, B. Hansen, Anesthesia and myasthenia gravis, Acta Anaesthesiol. Scand. 56 (2012) 17-22.

[5] Ah Ropper, Dr Gress, Mn Diringer, Dm Green, Sa Mayer, Tp Bleck, Treatment of the Critically Ill Patient With Myasthenia Gravis. Neurological and Neurosurgical Intensive Care, 4th ed., Lipincott Williams \& Wilkins, Philadelphia, PA, 2004, pp. 299-311.

[6] W.D. Phillips, A. Vincent, Pathogenesis of myasthenia gravis: update on disease types, models, and mechanisms, F1000Res 5 (2016).

[7] K. Lazaridis, S.J. Tzartos, Autoantibody specificities in myasthenia gravis; implications for improved diagnostics and therapeutics, Front. Immunol. 11 (2020) 212.

[8] M. De Baets, Oosterhuis H. Myasthenia Gravis, Printed in the United States, CRC Press, 1993.

[9] A. Vincent, Antibodies and receptors: From Neuromuscular Junction to Central Nervous System, Neuroscience (2020).

[10] M. Boldingh, A. Maniaol, C. Brunborg, et al., Geographical distribution of myasthenia gravis in Northern Europe - results from a population-based study from two countries, Neuroepidemiology 44 (2015) 221-231.

[11] P. Wirtz, M. Nijnuis, M. Sotodeh, et al., The epidemiology of myasthenia gravis, Lambert-Eaton myasthenic syndrome and their associated tumours in the northern part of the province of South Holland, J. Neurol. 250 (2003) 698-701.

[12] E. Decroos, L. Hobson-Webb, V. Juel, et al., Do acetylcholine receptor and striated muscle antibodies predict the presence of thymoma in patients with myasthenia gravis? Muscle Nerve (2014) 30-34.

[13] A. Marx, S. Porubsky, D. Belharazem, et al., Thymoma related myasthenia gravis in humans and potential animal models, Exp. Neurol. 270 (2015) 55-65.
[14] A. Marx, P. Hohenberger, H. Hoffmann, et al., The autoimmune regulator AIRE in thymoma biology, J. Thorac. Oncol. 5 (2010) S266-S272.

[15] M. Keijzers, A.M. Dingemans, H. Blaauwgeers, et al., 8 years' experience with robotic thymectomy for thymomas, Surg. Endosc. 28 (4) (2014) 1202-1208.

[16] B.M. Burt, X. Yao, J. Shrager, et al., Determinants of complete resection of thymoma by minimally invasive and open thymectomy: analysis of an international registry, J. Thorac. Oncol. 12 (1) (2017) 129-136.

[17] G. Marulli, J. Maessen, F. Melfi, et al., Multi-institutional European experience of robotic thymectomy for thymoma, Ann. Cardiothorac. Surg. 5 (January (1)) (2016) $18-25$.

[18] K.J. Na, C.H. Kang, Robotic thymectomy for advanced thymic epithelial tumor: indications and technical aspects, J. Thorac. Dis. 12 (2) (2020) 63-69.

[19] G. Wolfe, H. Kaminski, B. Inmaculada, et al., Randomized trial of thymectomy in myasthenia gravis, N. Engl. J. Med. 375 (2016) 511-522.

[20] G.I. Wolfe, H.J. Kaminski, I.B. Aban, et al., Long-term effect of thymectomy plus prednisone versus prednisone alone in patients with non-thymomatous myasthenia gravis: 2-year extension of the MGTX randomised trial, Lancet Neurol. 18 (3) (2019) 259-268.

[21] V. Christina, Myasthenia gravis and a rare complication of chemotherapy, Med. J. Aust. 182 (3) (2005) 120.

[22] M.C. Dalakas, Immunotherapy in myasthenia gravis in the era of biologics, Nat. Rev. Neurol. 15 (2) (2019) 113-124.

[23] C. Zhao, A. Rajan, Immune checkpoint inhibitors for treatment of thymic epithelial tumors: how to maximize benefit and optimize risk? Mediastinum 3 (2019).

[24] A.L. Mammen, A. Rajan, K. Pak, et al., Pre-existing antiacetylcholine receptor autoantibodies and B cell lymphopaenia are associated with the development of myositis in patients with thymoma treated with avelumab, an immune checkpoint inhibitor targeting programmed death-ligand 1, Ann. Rheum. Dis. 78 (1) (2019) $150-152$.

[25] Y. Shen, Z. Gu, J. Ye, et al., CT staging and preoperative assessment of resectability for thymic epithelial tumors, J. Thorac. Dis. 8 (4) (2016) 646-655.

[26] A. Evoli, E. Lancaster, Paraneoplastic disorders in thymoma patients, J. Thorac. Oncol. 9 (9 Suppl 2) (2014) S143-7.

[27] S.K. Padda, X. Yao, A. Antonicelli, et al., Paraneoplastic syndromes and thymic malignancies: an examination of the international thymic malignancy interest group retrospective database, J. Thorac. Oncol. 13 (3) (2018) 436-446. 